\title{
Derivation of predicted no effect concentrations (PNEC) for 2,4,6-trichlorophenol based on Chinese resident species
}

\author{
Xiaowei Jin ${ }^{a}$, Jinmiao Zha ${ }^{a}$, Yiping $\mathrm{Xu}^{\mathrm{a}}$, John P. Giesy ${ }^{\text {b,c,d,e }}$, Kristine L. Richardson ${ }^{\mathrm{f}}$, Zijian Wang ${ }^{\mathrm{a}, *}$ \\ a State Key Laboratory of Environmental Aquatic Chemistry, Research Center for Eco-Environmental Sciences, Chinese Academy of Sciences, P.O. Box 2871, Beijing 100085, China \\ ${ }^{b}$ Department of Veterinary Biomedical Sciences and Toxicology Centre, University of Saskatchewan, Saskatoon, Saskatchewan, Canada \\ ${ }^{\mathrm{c}}$ Department of Zoology and Center for Integrative Toxicology, Michigan State University, East Lansing, MI, USA \\ ${ }^{\mathrm{d}}$ Zoology Department, College of Science, King Saud University, P.O. Box 2455, Riyadh 11451, Saudi Arabia \\ e Department of Biology \& Chemistry, City University of Hong Kong, Kowloon, Hong Kong, SAR, China \\ ${ }_{\mathrm{f}}^{\mathrm{f}}$ Environmental Toxicology Program, Department of Environmental Sciences, University of California, Riverside, CA, USA
}

\section{A R T I C L E I N F O}

\section{Article history:}

Received 12 April 2011

Received in revised form 21 August 2011

Accepted 23 August 2011

Available online 28 September 2011

\section{Keywords:}

Water quality criteria

Chronic toxicity

Chinese resident species

Species sensitivity distribution

Assessment factor

probabilistic

\begin{abstract}
A B S T R A C T
2,4,6-Trichlorophenol (2,4,6-TCP) is a common chemical intermediate and a by-product of water chlorination and combustion processes, and is a priority pollutant of the aquatic environment in many countries. Although information on the toxicity of 2,4,6-TCP is available, there is a lack of information on the predicted no-effect concentration (PNEC) of 2,4,6-TCP, mainly due to the shortage of chronic and sitespecific toxicity data. In the present study, acute and sub-chronic toxicity of 2,4,6-TCP on six different resident Chinese aquatic species were determined. PNEC values were calculated and compared by use of two approaches: assessment factor (AF) and species sensitivity distribution (SSD). Values for acute toxicity ranged from $1.1 \mathrm{mg} \mathrm{L}^{-1}$ (Plagiognathops microlepis) to $42 \mathrm{mg} \mathrm{L}^{-1}$ (Corbicula fluminea) and the sub-chronic no observed effect concentrations (NOECs) ranged from $0.05 \mathrm{mg} \mathrm{L}^{-1}$ (Mylopharyngodon piceus) to $2.0 \mathrm{mg} \mathrm{L}^{-1}$ ( $C$. fluminea). PNECs obtained by the assessment factor approach with acute $\left(\mathrm{AF}=1000,0.001 \mathrm{mg} \mathrm{L}^{-1}\right)$ or chronic $\left(\mathrm{AF}=10,0.005 \mathrm{mg} \mathrm{L}^{-1}\right)$ toxicity data were one order of magnitude less than those from SSD methods $\left(0.057 \mathrm{mg} \mathrm{L}^{-1}\right)$. PNEC values calculated using SSD methods with a $50 \%$ certainty for 2,4,6-TCP was less than those obtained by use of the USEPA recommend final chronic value (FCV) method $\left(0.097 \mathrm{mg} \mathrm{L}^{-1}\right)$ and the one obtained by use of the USEPA recommend acute-tochronic (ACR) methods $\left(0.073 \mathrm{mg} \mathrm{L}^{-1}\right)$. PNECs derived using AF methods were more protective and conservative than that derived using SSD methods.
\end{abstract}

(c) 2011 Elsevier Ltd. All rights reserved.

\section{Introduction}

Chlorophenols are widely used synthetic organic compounds, employed as either synthesis intermediates in dyestuffs and pesticides or as biocides. Chlorophenols are commonly found in industrial wastes and are frequently detected water pollutants (Czaplicka, 2004; Gao et al., 2008). Among the chlorophenols,

\footnotetext{
Abbreviations: 2,4,6-TCP, 2,4,6-trichlorophenol; PNEC, predicted no-effect concentration; SSD, species sensitivity distribution; AF, application factor; NOEC, noobserved effect concentration; LOEC, lowest observed effect concentration; MATC, maximum allowable toxicant concentration; CCC, criterion continuous concentration; FAV, final chronic value; FCV, final chronic values; ACRs, acute to chronic ratios; FACR, final acute-to-chronic ratios; WQC, water quality criteria; SGR, specific growth rate.

* Corresponding author. Address: State Key Laboratory of Environmental Aquatic Chemistry, Research Center for Eco-Environmental Sciences, Shuangqing Rd. 18, Haidian District, Beijing 100085, China. Tel.: +8610 6284 9140; fax: +86 106292 3543.

E-mail address: wangzj@rcees.ac.cn (Z. Wang).
}

2,4,6-trichlorophenol (2,4,6-TCP), which has been used since the early 1930 s, and is the most frequently detected chlorophenol in surface waters. 2,4,6-TCP, is an intermediate in the production of chlorophenoxy acid herbicides. Furthermore, 2,4,6-TCP is a byproduct of disinfection of water by use of chlorination and of combustion. Due to toxicity to aquatic life, resistance to degradation, and potential for bioaccumulation, 2,4,6-TCP is a priority pollutant of aquatic environments in the USA as well as China (Yin et al., 2003a). Waters from over 600 sites in seven major watersheds and three drainage areas in China contained detectable concentrations of $2,4,6$-TCP in $54.4 \%$ (median $=2.0 \mathrm{ng} \mathrm{L}^{-1}$, range $<1.4$ $28650.0 \mathrm{ng} \mathrm{L}^{-1}$ ) (Gao et al., 2008). Therefore, the deleterious effects and ecological risk of 2,4,6-TCP on aquatic ecosystems have raised concern by regional and central government agencies in China.

An important step in the ecological risk assessment of chemicals is determination of the maximum concentration at which the ecosystem is protected. That is, the predicted no-effect concentration (PNEC). PNECs are usually derived for a limited number of species in laboratory-based toxicity tests which have well-defined 
protocols. Information on the toxicity of 2,4,6-TCP to a wide range of aquatic species has been reported (LeBlanc and Bionomics, 1984; Smith et al., 1991; Kishino and Kobayashi, 1995; Radix et al., 1999). However, toxicity data, especially for chronic effects, on resident species, especially for local species was unavailable to develop site-specific assessments in China (Yin et al., 2003a). Thus, the PNEC for 2,4,6-TCP based on Chinese resident species had not been determined. However, selecting resident species for determining PNEC values is confounded by variations among ecosystems throughout China. Different ecosystems contain different biological constituents, and a concentration threshold harmless in one ecosystem may lead to irreversible toxic effects on others. Therefore, the USEPA guidelines state that only wildlife species distributed throughout North America can be used as test species to derive the water quality criteria (WQC), such as PNEC, for the protection of freshwater and marine ecosystems (USEPA, 1985). In Australia, species sensitivity distributions (SSDs) and protective concentrations for 95\% (PC95) of local species are being used to derive water-quality guidelines for toxicants (ANZECC \& ARMCANZ, 2000; Hose and Van den Brink, 2004). It has been suggested that site-specific WQC based on indigenous aquatic biota should be developed for China (Yin et al., 2003a, 2003b).

Two basic methods for deriving PNECs are in use or proposed for use in hazard assessments (USEPA, 1985; OECD, 1995; ECB, 2003). To arrive at a criterion, a simple deterministic approach uses a critical parameter of the available toxicity data (lowest $\mathrm{LC}_{50}$ or lowest NOEC) and divides it by a series of assessment factors (safety or uncertainty), usually in the range of 1-1000. The values of the assessment factors (AF) depend on the extent and nature of the toxicity data. The factors are inversely proportional to the availability and quality of toxicity data. Due to their simplicity and minimal data requirements, methods that use AFs are globally used in preliminary ecological risk assessments. However, these methods are also limited because assessment factors are somewhat arbitrary and uncertainty of the PNEC is generally not quantified (Slooff, 1992; Chapman et al., 1998). Another method for deriving the PNEC, species sensitivity distributions (SSDs), is based on the assumption that variation in chemical sensitivity among species can be described by assessment of the distributions of values (Aldenberg and Slob, 1993; Aldenberg and Jaworska, 2000; Newman et al., 2000; Posthuma et al., 2002). After estimation of its parameters, the distribution can be used to predict a concentration value which does not exceed the NOEC for a predefined percentage of the species, such as $95 \%$. The SSD method can produce more robust PNECs, but adequate chronic toxicity data is only available for select taxonomic groups, and is lacking for most new and existing substances (Sijm et al., 2001).

In the current study, acute and chronic toxicity tests were conducted for six native species, including three fishes, two invertebrates and one hygrophyte, which were collected from the Yangtze River. Toxicity data for 2,4,6-TCP was used to derive PNEC values based on both the assessment factor method and the species sensitivity distribution method. The aims of this study were (1) to provide further 2,4,6-TCP toxicity data for use in ecological risk assessment, especially for Chinese local 2,4,6-TCP pollution issues, (2) to discuss the potential establishment of site-specific water quality criteria for 2,4,6-TCP.

\section{Materials and methods}

\subsection{Test species and conditions}

Six species resident in China, including two benthic invertebrates (Asian clam Corbicula fluminea and Freshwater shrimp Macrobrachium superbum); three fish (Black carp Mylopharyngodon piceus, Smallscale yellowfin Plagiognathops microlepis and Whitefish Erythroculter ilishaeformis) and one hydrophyte (Greater duckweed Soirodela polyrhiza) were selected for study based on their distribution, economic significance and adaptability to laboratory conditions. These test species were provided by the Huazhong Agricultural University (Wuhan, China), and were acclimated to test conditions $\left(24 \pm 1^{\circ} \mathrm{C}, \mathrm{pH} 7.24 \pm 0.16\right)$ for more than 2 weeks prior to the experiments.

All test species were held in water with a minimum average dissolved oxygen concentration of approximately $80 \%$ saturation. The $\mathrm{pH}$ averaged 7.65. Conductivity and hardness averaged

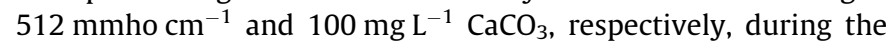
study. Strip chart records of temperature showed that an average temperature of $24 \pm 1^{\circ} \mathrm{C}$ was maintained for all tests.

\subsection{Test chemical}

Analytical grade 2,4,6-trichlorophenol $\left(\mathrm{HOC}_{6} \mathrm{H}_{2} \mathrm{Cl}_{3}\right.$ ) (CAS RN: 88-06-2) of 98.0\% purity was purchased from ACROS Organics, USA. Tap water, dechlorinated with activated carbon, was used for all tests. The dilution water quality parameters were measured as follows: $\mathrm{pH}=7.24 \pm 0.16$; dissolved oxygen concentration (DO) $=8.43 \pm 0.24 \mathrm{mg} \mathrm{L}^{-1}$, total organic carbon (TOC) content $=$ $0.017 \mathrm{mg} \mathrm{L}^{-1}$, and total hardness $=100 \mathrm{mg} \mathrm{L}^{-1}$.

\subsection{Acute toxicity tests}

All acute tests, including toxicity tests on fishes, macroinvertebrates and the hydrophyte, followed international standard guidelines (ASTM, 1993; USEPA, 1993; OECD, 2002). 96-h static-renewal acute 2,4,6-TCP toxicity tests were conducted in a temperaturecontrolled room. Test solutions were maintained by daily renewal of $90 \%$ of the test solution. There were five treatments (nominal concentration) of test chemical plus a control and three replicates of each treatment, each beaker (replicate) containing 10 test organisms. Test concentrations were chosen based on results of preliminary range-finding tests (data not shown). Dissolved oxygen, conductivity, temperature, $\mathrm{pH}$, and salinity were measured with a multiparameter water quality meter (YSI Model $85 \mathrm{~m}$; Yellow Springs, $\mathrm{OH}$ ).

Juveniles of $M$. piceus $(17.7 \pm 0.40 \mathrm{~mm}, 38.0 \pm 2.20 \mathrm{mg}), \quad P$. microlepis $(16.4 \pm 0.37 \mathrm{~mm}, 26.7 \pm 1.90 \mathrm{mg}$ ) and E. ilishaeformis $(23.6 \pm 0.29 \mathrm{~mm}, 55.0 \pm 2.00 \mathrm{mg})$ were tested in glass beaker containing $1000 \mathrm{~mL}$ test solution. Nominal concentrations used in these studies were $0,0.50,1.00,1.50,2.00$ and $2.50 \mathrm{mg} \mathrm{L}^{-1} 2,4,6$ TCP for all three test fishes. $C$. fluminea with a mean shell length of $20.80 \pm 0.20 \mathrm{~mm}$, a mean shell height of $19.40 \pm 0.20 \mathrm{~mm}$ and mean body weight of $3.66 \pm 0.40 \mathrm{~g}$ wet wt. was tested in glass beaker containing $1000 \mathrm{~mL}$ test solution. M. superbum (39.63 \pm $0.47 \mathrm{~mm}, 0.87 \pm 0.08 \mathrm{~g}$ ) was tested in glass container containing $4000 \mathrm{~mL}$ test solution. Nominal concentrations for $C$. fluminea and $M$. superbum used in the study were $0,10.0,20.0,30.0,40.0$, $50.0 \mathrm{mg} \mathrm{L}^{-1}$ and $0,0.40,0.80,1.60,3.20,6.40 \mathrm{mg} \mathrm{L}^{-1} 2,4,6-\mathrm{TCP}$, respectively. During the exposure, beakers were held in an incubator at $24 \pm 1{ }^{\circ} \mathrm{C}$ with $16 \mathrm{~L}$ : $8 \mathrm{D}$ photoperiod. Test organisms were not fed during the exposure period. Mortality and abnormal behavior were monitored daily and dead organisms were removed immediately.

S. polyrhiza was cultured in the laboratory in half-strength Hoagland's medium (Yuan and Yang, 1983) under $2000 \mathrm{~lx}$ and $24 \pm 1{ }^{\circ} \mathrm{C}$. The $\mathrm{IC}_{50}$ (median inhibitory concentration) tests were conducted in a series of $90 \mathrm{~mm}$ glass crystallizing dishes. Each container contained about $200 \mathrm{~mL}$ of test medium and 10 fronds of $S$. polyrihiza. The nominal concentrations used in the definitive studies were $0,1.00,2.50,5.00,10.0$ and $25.0 \mathrm{mg} \mathrm{L}^{-1} 2,4,6$-TCP. Plants were maintained at $24 \pm 1{ }^{\circ} \mathrm{C}$ with $24 \mathrm{~h}$ light. The number of fronds 
in each beaker was counted every day. No significant mortality or adverse effect occurred during the test period in the control treatment for each species.

\subsection{Sub-chronic toxicity tests}

Sub-chronic continuous exposures of six native species to 2,4,6TCP were conducted in static-renewal diluters with daily replacement. Test conditions and solution renewal procedures were as above. Six nominal concentrations (five treatments plus a control) of 2,4,6-TCP were used as experimental treatments, each replicated three times. Test concentrations were selected on the basis of data obtained from the preceding acute toxicity tests. Water quality parameters were measured every $2 \mathrm{~d}$ as above.

Three-week tests of survival of $M$. superbum $(39.63 \pm 0.47 \mathrm{~mm}$, $0.87 \pm 0.08 \mathrm{~g})$ and $C$. fluminea $(20.80 \pm 0.20 \mathrm{~mm}, 3.66 \pm 0.40 \mathrm{~g})$ were conducted in glass beakers which contained $4000 \mathrm{~mL}$ or $1000 \mathrm{~mL}$ of test solution, respectively. Test organisms were fed according to standard guidelines for conducting chronic tests with macroinvertebrates (ASTM, 1993). Test organisms were fed daily a solution of microalgae concentrate prepared from instant algae shellfish diet and Nannochloropsis sp concentrate. At the end of test, the 21d no-observed effect concentrations (NOEC) and the lowest observed effect concentrations (LOEC) were derived by analyzing survival rate and behavioral effects of test organisms.

Twenty-eight days sub-chronic growth inhibition toxicity using M. piceus (17.65 $\pm 0.40 \mathrm{~mm}, 38.0 \pm 2.20 \mathrm{mg})$, P. microlepis $(16.40 \pm$ $0.37 \mathrm{~mm}, 26.7 \pm 1.90 \mathrm{mg})$ and E. ilishaeformis $(23.59 \pm 0.29 \mathrm{~mm}$, $55.0 \pm 2.00 \mathrm{mg}$ ) at early life stages were tested in glass beakers which contained $1000 \mathrm{~mL}$ of test solution. During exposure, juvenile fishes were fed with a commercial granule food (Trea, Germany) at a rate of $0.1 \%$ body weight per day and newly hatched brine shrimp (Artemia nauplii) twice a day. At the end of the test, length and weight of each fish was measured and survival rate determined for each concentration, from which NOEC and LOEC were derived. Specific growth rate (SGR) was calculated because it is less dependent on the initial size of the fish and on the time between measurements than the other growth measurements such as relative growth rate (RGR) (Mallett et al., 1997). The SGR was calculated (Eq. (1)) (Crossland, 1985).

$\mathrm{SGR}=((\ln ($ final mass $)-\ln ($ initial mass $))$

$$
\times 100) \text { /days of exposure }
$$

At the end of the sub-chronic toxicity test, all animals survived in the control.

Sub-chronic toxicity of S. polyrihiza was conducted in $90 \mathrm{~mm}$ glass crystallizing dishes with $200 \mathrm{~mL}$ of test medium for $10 \mathrm{~d}$. At the end of the test, chlorophyll was measured using an ultraviolet and visible spectrophotometer (Zhang and Jin, 1997), from which NOEC and LOEC were derived.

\subsection{Quantification of 2,4,6-TCP}

During the acute and chronic toxicity exposure, samples of water containing 2,4,6-TCP were randomly collected during the experiments from control, and least, medium, and greatest dosage concentrations. Triplicate samples were made for water from one tank of each concentration. Samples were spiked with surrogate standard (Biphenol A-d16), adjusted to $\mathrm{pH}<2$ with $6 \mu \mathrm{M}$ hydrochloride buffer and extracted with SPE using C18 cartridge. The cartridges were eluted with $10 \mathrm{~mL}$ dichloromethane (DCM). All of the extracts were evaporated under a gentle stream of nitrogen. In order to reduce the polarity of phenols so that they could be separated by gas chromatography, dried samples were derivatized in a heating block $60{ }^{\circ} \mathrm{C}$ for $2 \mathrm{~h}$ with BSTFA and $1 \%$ TMCS. Samples were maintained at $4^{\circ} \mathrm{C}$ in brown polypropylene bottles in the dark until analysis.

Concentrations of 2,4,6-TCP were measured by use of an Agilent 6890 gas chromatograph equipped with Agilent MSD 5975 mass spectrometer. The capillary column of $30 \mathrm{~m} \times 0.25 \mathrm{~mm}$ i.d. $0.25 \mu \mathrm{m}$ HP-5 was used. Gas chromatography (GC) oven temperature was programmed from $40{ }^{\circ} \mathrm{C}$ to $300^{\circ} \mathrm{C}$ via a ramp of $10{ }^{\circ} \mathrm{C} \mathrm{min}-1$ and maintained at $40{ }^{\circ} \mathrm{C}$ for 2 min and at $300{ }^{\circ} \mathrm{C}$ for $15 \mathrm{~min}$. The instrument was operated in constant pressure mode. Sample injection $(1 \mu \mathrm{L})$ was in splitless mode. The mass spectrophotometer (MS) was operated in full-scan mode from $\mathrm{m} / \mathrm{z}$ 50-700 for qualitative analysis and in selected ion monitoring (SIM) mode for quantitative analysis. The inlet and MS transfer line were maintained at $250{ }^{\circ} \mathrm{C}$, and the ion source temperature was $300{ }^{\circ} \mathrm{C}$. The mass spectra were analyzed by the techniques of retention time lock (RTL) and deconvolution report software (DRS) (software provided by Agilent).2,4,6-TCP in control aquaria and in blanks was less than detection limits $\left(1.40 \mathrm{ng} \mathrm{L}^{-1}\right)$. Measured 2,4,6-TCP concentrations in the treated fish species collected during experiments varied from $88.7 \%$ to $107.9 \%$ of nominal concentrations (mean 95.1\%, $n=72$ ). Therefore, all subsequent acute and chronic toxicity results were expressed on nominal concentrations of 2,4,6-TCP.

\subsection{Statistical analysis}

The endpoint for the acute tests was death except for S. polyrihiza (for growth). The $\mathrm{LC}_{50}$ and $95 \%$ confidence intervals for each test was calculated using Probit Program Version 1.5 (USEPA, 1990). $\mathrm{IC}_{50}$ (for S. polyrihiza) for growth inhibition were determined using standard method recommended by Organization for Economic Cooperation and Development (OECD, 2002). The data from chronic tests were analyzed using SPSS Version 17 software. The experimental data were checked for homogeneity of variance among treatments by use of Levene's test. The data were subjected to one-way analysis of variance followed by Dunnett's multiple comparison tests once the assumptions were met. Statistical differences were considered to be significant at $p \leqslant 0.05$. The NOEC was defined as the greatest concentration that did not result in a significant effect compared with the control. The LOEC was defined as the least concentration that did result in a significant effect compared with the control, The maximum allowable toxicant concentration (MATC) was equal to the geometric average of NOEC and LOEC (USEPA, 1985).

\subsection{Development of PNEC value}

PNECs were calculated by use of the traditional deterministic AF approach, along with SSD methods to gain $\mathrm{HC}_{5}$ (hazardous concentration for $5 \%$ of species) values. $\mathrm{AF}=1000$ was applied to the least acute $\mathrm{LC}_{50}$, and $\mathrm{AF}=10$ applied to the least NOEC value (OECD, 1995; ECB, 2003). Lower (5\% confidence), median (50\% confidence), and upper (95\% confidence) $\mathrm{HC}_{5}$ by use of the BurrliOZ program (CSIRO v I.O.13; Perth, Australia) (Campbell et al., 2000). BurrliOZ fits the Burr type III distribution (Shao, 2000), which is a flexible three-parameter distribution that provides good approximations of many commonly used distributions such as the log-normal, log-logistic, and Weibull (Hose and Van den Brink, 2004).

Final chronic values (FCV) were calculated by use of the USEPA method for calculating National Ambient Water Quality Criteria (USEPA, 1985). When chronic data are lacking, the FCV was calculated by dividing the final acute values (FAV) by final acute-tochronic ratios (FACR). Using only the four most sensitive acute toxicity values $\left(\mathrm{LC}_{50}\right.$ or $\mathrm{EC}_{50}$ ), the FAV calculation assumes a log triangle distribution of species sensitivity. The FAV is the 5th centile from the SSD. If at least eight chronic toxicity data are available for 
species from eight different families, FCV was calculated using the produce same as FAV calculation (USEPA, 1985).

\section{Results}

\subsection{Acute toxicity}

2,4,6-TCP was acutely toxic to all six native species at the concentrations tested in this study. Time-dependent $\mathrm{LC}_{50}$ values and 95\% confidence intervals (CI) are presented (Table 1). P. microlepis was the most sensitive among the 3 tested fish species, and the 96-h $\mathrm{LC}_{50}$ was $1.10 \mathrm{mg} \mathrm{L}^{-1}$ (95\% CI, 0.38-1.36 $\mathrm{mg} \mathrm{L}^{-1}$ ), followed by $M$. piceus and E. ilishaeformis with a $96-\mathrm{h} \mathrm{LC}_{50} \mathrm{~S}$ of 1.22 (1.12$1.31) \mathrm{mg} \mathrm{L}^{-1}$ and $1.99(1.82-2.28) \mathrm{mg} \mathrm{L}^{-1}$, respectively. Among the two invertebrate species, the $96-\mathrm{h} \mathrm{LC}_{50}$ for M. superbum was 2.05 (1.61-2.76) $\mathrm{mg} \mathrm{L}^{-1}$, which was less sensitive than $C$. fluminea with a $96-\mathrm{h} \mathrm{LC}_{50}$ of $41.9(35.5-58.2) \mathrm{mg} \mathrm{L}^{-1}$. Twenty-four hours $\mathrm{LC}_{50}$ values of 2,4,6-TCP were significantly higher than those of 48 and $72 \mathrm{~h}$ for each of the tested organisms. When treatment period exceeded $72 \mathrm{~h}$, variation in the $\mathrm{LC}_{50}$ value for each test organism decreased.

Significantly less frond growth was observed in the 4-d $S$. polyrhiza growth inhibition test. The toxicity of 2,4,6-TCP on growth of $S$. polyrhiza was directly proportional to concentration of 2,4,6-TCP (Fig. 1). The $96-\mathrm{h} \mathrm{IC} \mathrm{IC}_{50}$ of $S$. polyrhiza was calculated to be $8.49 \mathrm{mg} 2,4,6-\mathrm{TCP} \mathrm{L}^{-1}$.

\subsection{Sub-chronic toxicity}

The six test species exhibited different sensitivities to 2,4,6-TCP exposure (Table 1 ). Results of the $21 \mathrm{~d}$ sub-chronic toxicity test showed that $M$. superbum was more sensitive than $C$. fluminea to the exposure of 2,4,6-TCP based on survival. The NOECs for the two invertebrates were $0.10 \mathrm{mg} \mathrm{L}^{-1}$ and $2.00 \mathrm{mg} \mathrm{L}^{-1}$; and their LOECs were $0.20 \mathrm{mg} \mathrm{L}^{-1}$ and $4.00 \mathrm{mg} \mathrm{L}^{-1}$; respectively. The calculated MATC values were $0.14 \mathrm{mg} \mathrm{L}^{-1}$ and $2.83 \mathrm{mg} \mathrm{L}^{-1}$, respectively.

In the $28 \mathrm{~d}$, sub-chronic growth inhibition toxicity test on early life stages of M. piceus, P. microlepis and E. ilishaeformis, all individuals survived the testing period, and the juvenile SGR were $3.85 \%$, $4.73 \%$ and $2.95 \%$ per day in the control, respectively. For M. piceus, the $0.10 \mathrm{mg} \mathrm{L}^{-1}$ and greater concentrations significantly reduced the juvenile SGR $(P<0.05$; ANOVA; Fig. 2A). For $P$. microlepis, juvenile SGR in the $0.20 \mathrm{mg} \mathrm{L}^{-1}$ and greater concentrations were significantly less than that in the control (Fig. 2B). For E. ilishaeformis, the critical value was $0.40 \mathrm{mg} \mathrm{L}^{-1}$ (Fig. 2C). Based on the statistical analysis, NOECs for growth inhibition were $0.05 \mathrm{mg} \mathrm{L}^{-1}$, $0.10 \mathrm{mg} \mathrm{L}^{-1}$ and $0.30 \mathrm{mg} \mathrm{L}^{-1}$, their LOECs were $0.10 \mathrm{mg} \mathrm{L}^{-1}$, $0.20 \mathrm{mg} \mathrm{L}^{-1}$ and $0.40 \mathrm{mg} \mathrm{L}^{-1}$, and the calculated MATC were

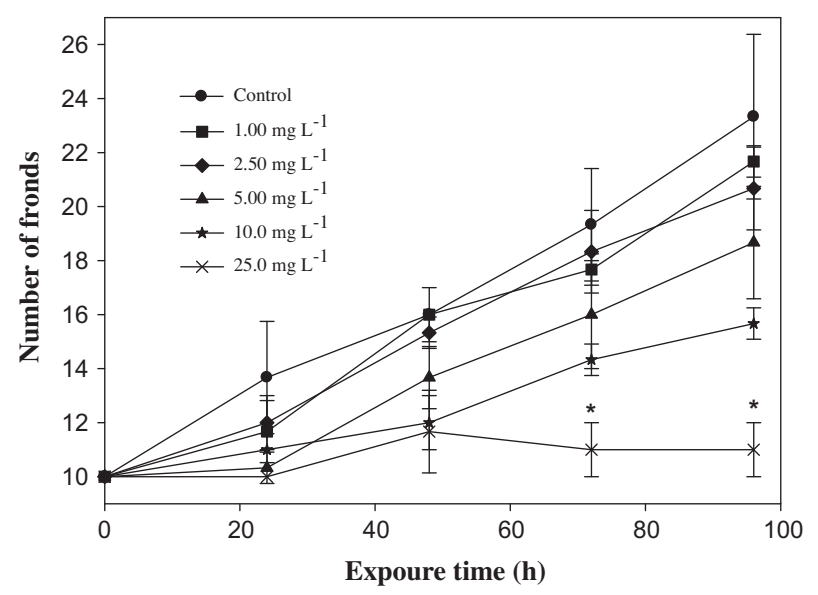

Fig. 1. Effect of 4-d exposure to 2,4,6-trichlorophenol on Soirodela polyrhiza growth rate (number of fronds grown, starting from the initial 10 fronds). *Significant differences from the values of the control at $p<0.05$.

$0.07 \mathrm{mg} \mathrm{L}^{-1}, 0.14 \mathrm{mg} \mathrm{L}^{-1}$ and $0.35 \mathrm{mg} \mathrm{L}^{-1}$ for M. piceus, P. microlepis and E. ilishaeformis, respectively.

In the 10 -d toxicity test with $S$. polyrihiza chlorophyll content decreased gradually as a function of 2,4,6-TCP concentration. Chlorophyll content was $96.1 \%$ of control at $1.00 \mathrm{mg} \mathrm{L}^{-1}$, and $70.7 \%$ at $25.0 \mathrm{mg} \mathrm{L}^{-1}$. The NOEC, LOEC and MATC were $1.00 \mathrm{mg} \mathrm{L}^{-1}$, $2.50 \mathrm{mg} \mathrm{L}^{-1}$ and $1.58 \mathrm{mg} \mathrm{L}^{-1}$, respectively (Fig. 3).

\subsection{Predicted no effect concentrations for 2,4,6-TCP}

A total of 10 (six from this study and four gained from literature (Yin et al., 2003a)) chronic toxicity data sets for resident species, including 5 fishes, 4 invertebrates, and 1 hydrophyte, were used to derive the PNEC value for 2,4,6-TCP in Chinese waters. The results of the PNEC calculations using the various methods are shown in Table 2.

SSD were developed from log-logistic distributions fitted to resident chronic data (Table 2 and Fig. 4). The median $\mathrm{HC}_{5}$ value for 2,4,6-TCP was 0.057 (0.031-0.117) $\mathrm{mg} \mathrm{L}^{-1}$.

A FAV for 2,4,6-TCP was determined using the four most sensitive acute toxicity results (Fig. 5A). Dividing the FAV by FACR (10.14), the FCV was $0.073 \mathrm{mg} \mathrm{L}^{-1}$. Using the four most sensitive maximum-allowed toxicant concentrations (MATCs), a FCV of $0.097 \mathrm{mg} \mathrm{L}^{-1}$ was derived (Fig. 5B). The rationale for use of MATCs is that the MATC gives a more likely estimate of the true NOEC, since treatment concentrations are rather arbitrarily chosen (USEPA, 1985).

Table 1

Acute and chronic toxicity data for Chinese resident species used to calculate PNEC values for 2,4,6-trichlorophenol.

\begin{tabular}{|c|c|c|c|c|c|c|}
\hline \multirow[t]{2}{*}{ Species } & \multicolumn{2}{|l|}{ Acute toxicity } & \multicolumn{3}{|l|}{ Chronic toxicity } & \multirow[t]{2}{*}{ References } \\
\hline & Measurement and endpoint & Concentration $(95 \% \mathrm{CI})\left(\mathrm{mg} \mathrm{L}^{-1}\right)$ & Measurement and endpoint & Concentration $\left(\mathrm{mg} \mathrm{L}^{-1}\right)$ & $\mathrm{ACRs}^{\mathrm{b}}$ & \\
\hline C. fluminea & $96 \mathrm{~h} \mathrm{LC}_{50}$ & $41.9(35.5-58.2)$ & 21d NOEC, Survival & 2.00 & 14.8 & In this study \\
\hline M. superbum & $96 \mathrm{~h} \mathrm{LC}_{50}$ & $2.05(1.61-2.76)$ & 21d NOEC, Survival & 0.10 & 14.6 & In this study \\
\hline M. piceus & $96 \mathrm{~h} \mathrm{LC}_{50}$ & $1.22(1.25-1.61)$ & 28d NOEC, Growth & 0.05 & 17.4 & In this study \\
\hline P. microlepis & $96 \mathrm{~h} \mathrm{LC}_{50}$ & $1.10(0.38-1.36)$ & 28d NOEC, Growth & 0.10 & 7.86 & In this study \\
\hline E. ilishaeformis & $96 \mathrm{~h} \mathrm{LC}_{50}$ & $1.99(1.82-2.28)$ & 28d NOEC, Growth & 0.30 & 5.69 & In this study \\
\hline S. polyrhiza & $96 \mathrm{~h} \mathrm{IC}_{50}$ & 8.49 & 10d NOEC, Chlorophyll & 1.00 & 5.37 & In this study \\
\hline D. magna ${ }^{\mathrm{a}}$ & - & - & 21d NOEC, Reproduction & 0.20 & 6.18 & Yin et al. (2003a) \\
\hline C. auratus ${ }^{\mathrm{a}}$ & - & - & 30d NOEC, Survival & 0.25 & 12.3 & Yin et al. (2003a) \\
\hline C. idellus ${ }^{\mathrm{a}}$ & - & - & 60d NOEC, Growth & 0.50 & 4.99 & Yin et al. (2003a) \\
\hline B. bufo gargarizans ${ }^{\mathrm{a}}$ & - & - & 30d NOEC, Growth & 0.50 & 12.2 & Yin et al. (2003a) \\
\hline
\end{tabular}

a Chronic toxicity data (both of NOEC and ACR) for these four Chinese resident species were published by Yin et al. (2003a).

b ACRs stands for acute-to-chronic ratios, which are calculated by dividing acute $\mathrm{LC}_{50}$ or $\mathrm{EC}_{50}$ values by chronic maximum allowable toxicant concentrations (MATC). 

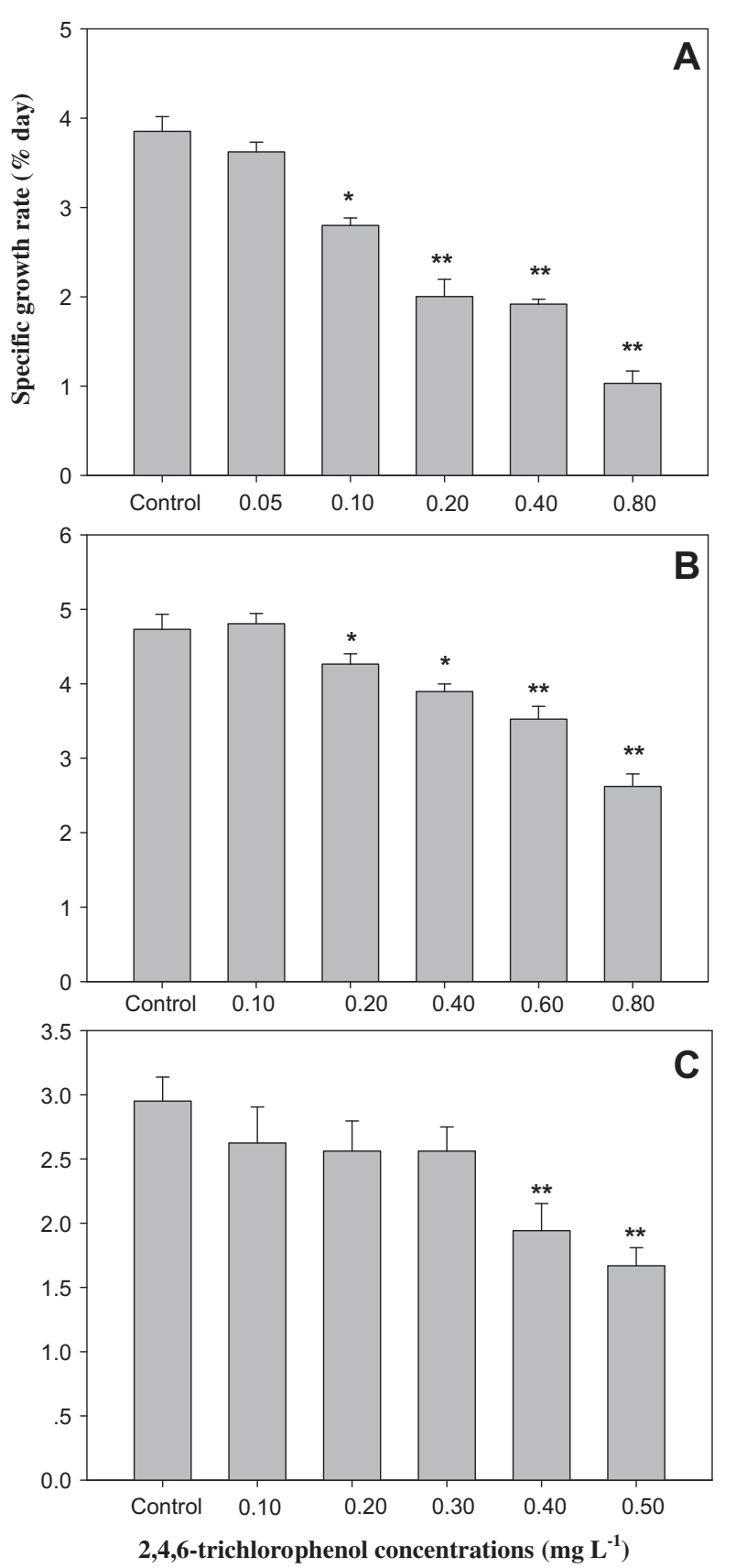

Fig. 2. Effect of 28-d exposure to 2,4,6-trichlorophenol on the specific growth rate of the early life stages of Mylopharyngodon piceus (A), Plagiognathops microlepis (B) and Erythroculter ilishaeformis (C). Data are presented as means \pm standard deviation (SD). ${ }^{*}$ and ${ }^{* *}$ Significant differences from the values of the control at $p<0.05$ and $p<0.01$, respectively.

The PNEC derived from the SSD were compared to a PNEC calculated using the AF approach. The least $\mathrm{LC}_{50}$ was $1.10 \mathrm{mg} \mathrm{L}^{-1}$ for $P$. microlepis and this $\mathrm{LC}_{50}$ was divided by an $\mathrm{AF}$ of 1000 . The least NOEC is $0.05 \mathrm{mg} \mathrm{L}^{-1}$ from the M. piceus growth inhibition test and this NOEC was divided by an AF of 10 . The resulting traditionally derived PNECs based on the use of AF of 1000 and 10 for 2,4,6TCP were 0.001 and $0.005 \mathrm{mg} \mathrm{L}^{-1}$ respectively.

\section{Discussion}

The results of the present study indicated that 2,4,6-TCP is toxic to resident freshwater aquatic organisms. Among the different spe-

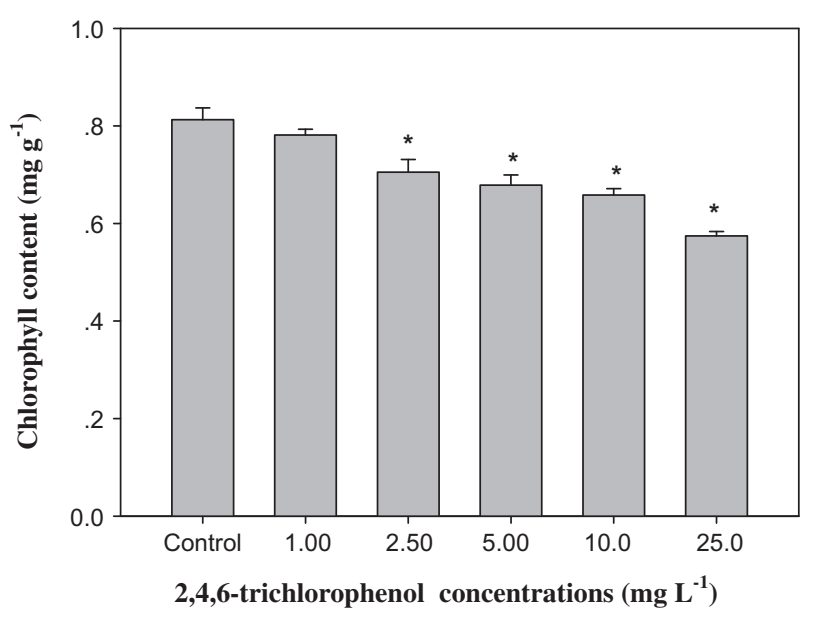

Fig. 3. Effect of 10-d exposure to 2,4,6-trichlorophenol on chlorophyll content of Soirodela polyrhiza. Data are presented as means \pm standard deviation (SD). *Significant differences from the values of the control at $p<0.05$.

cies, the fishes were more sensitive than aquatic macroinvertebrates and the hydrophyte was the least sensitive. Fishes and macroinvertebrates were more sensitive to chronic exposures than hydrophytes. C. fluminea was less sensitive to 2,4,6-TCP than the other invertebrates $M$. superbum, which might be due to decreased uptake of 2,4,6-TCP caused by the shell of $C$. fluminea. The three juvenile fish exhibited similar tolerances to both acute and chronic exposures, which might be due to the fact that all three species belong to the same family (Cyprinidae). However, the $96 \mathrm{~h} \mathrm{LC} 50$ values for 2,4,6-TCP for three fishes in this study (1.1-2.0 $\mathrm{mg} \mathrm{L}^{-1}$ ) were less than the $96 \mathrm{~h} \mathrm{LC}_{50}$ values for 2,4,6-TCP $\left(3.5-4.3 \mathrm{mg} \mathrm{L}^{-1}\right)$ for other members in Cyprinidae (Yin et al., 2003a). Chronic toxicity for fishes of the family Cyprindae exhibited the same trend of increased sensitivity of the fish in the current study as compared to previous tests. This discrepancy is most likely due to the fact that the present study employed younger test fishes, which are more sensitive to toxic compounds. The chronic toxicity of the other species tested in the present study cannot be compared with previous studies due to lack of chronic toxicity data for other local species in China.

The PNEC values, which were calculated for Chinese resident species, by use of different methods, are given (Table 2). The PNEC calculated using SSD methods for 2,4,6-TCP was 0.057 (0.031$0.117) \mathrm{mg} \mathrm{L}^{-1}$, which is both less than the PNEC obtained with USEPA-recommend FCV method and the one obtained with USEPA-recommend ACR methods. However, they are numerically of the same order of magnitude. The PNEC values obtained by AF methods (ranged from 0.001 to $0.005 \mathrm{mg} \mathrm{L}^{-1}$ ) were less than those derived by use of SSD methods by a factor of 11.4-57.0. Extrapolating from the least acute toxicity data $\left(\mathrm{LC}_{50}\right)$ with the assessment factor 1000, the obtained PNEC for 2,4,6-TCP was less than those obtained by extrapolation from chronic toxicity data (NOEC) with the assessment factor 10 . In general, AF methods produced values for PNEC were more protective and conservative. The PNECs for 2,4,6-TCP obtained from SSD methods is of the same order of magnitude with USEPA recommend methods.

In EU risk assessments, the PNEC is usually derived from the either the AF methods or the SSD approach (based on calculated $\mathrm{HC}_{5}$ values) (ECB, 2003). Assessment factors are recognized as a conservative approach for dealing with uncertainty in assessing risks posed by chemicals (Chapman et al., 1998). However, current applications of AFs are based on policy rather than on empirical results, and thus result in values that are protective, but not predictive of effects. Specifically addressing ACRs, Chapman et al. (1998) 
Table 2

PNEC values for 2,4,6-trichlorophenol derived using either SSD or traditional assessment factor approach.

\begin{tabular}{|c|c|c|c|c|c|}
\hline & \multicolumn{2}{|l|}{ AF methods } & \multicolumn{2}{|c|}{ USEPA methods } & \multirow{2}{*}{ SSD methods median $\mathrm{HC}_{5}$ value } \\
\hline & Lowest $\mathrm{LC}_{50} / 1000$ & Lowest NOEC/10 & $\mathrm{FACR}^{\mathrm{a}}=10.14$ & $\overline{\mathrm{FCV}^{\mathrm{b}}}$ & \\
\hline $\operatorname{PNEC}\left(\mathrm{mg} \mathrm{L}^{-1}\right)$ & 0.001 & 0.005 & 0.073 & 0.097 & $0.057(0.031-0.117)$ \\
\hline
\end{tabular}

a FACR stands for final acute-to-chronic ratio, which is the average of ACRs for the different aquatic species.

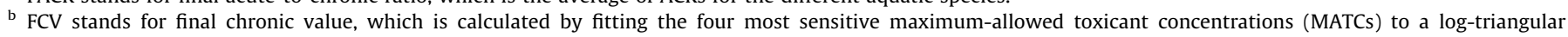
distribution.

c Calculated by fitting all no-observed effect concentrations (NOEC) to a Burr III distribution.

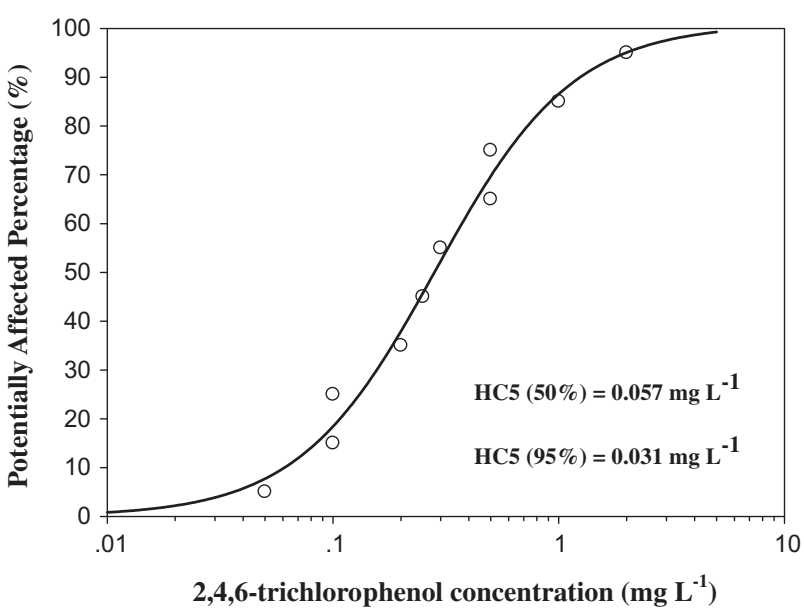

Fig. 4. PNECs for 2,4,6-trichlorophenol calculated using the species sensitivity distribution (SSD) approach.

cited multiple studies to show that measured ACRs can vary from 1 to 20000. In view of this, it is unreasonable to apply a generic safety factor (whether of 10 or some other magnitude) across species and across substances. A criterion continuous concentration (CCC) of $0.23 \mathrm{mg} \mathrm{L}^{-1}$, derived from published ACRs (Yin et al., 2003a) would not provide enough protection to the native species M. superbum, M. piceus and P. microlepis because the NOEC values determined in the present study for these species were all less than the CCC $\left(0.10 \mathrm{mg} \mathrm{L}^{-1}, 0.05 \mathrm{mg} \mathrm{L}^{-1}, 0.10 \mathrm{mg} \mathrm{L}^{-1}\right.$, respectively).

The main difference between USEPA-recommend FCV and SSD methods is the selection of the shape of the distribution that is used for the extrapolations. The USEPA (1985) assumes the four data points nearest the 5 th centile with a log-triangular distribution. The ANZECC \& ARMCANZ (2000) methodology utilizes a Burr III distribution, which is a flexible three-parameter distribution that provides good approximations to many commonly used distributions such as log-normal, log-logistic, or Weibull (Hose and Van den Brink, 2004), for all data as described by Shao (2000). Other differences between the FVC and SSD methods include the type and quantity of data used in the extrapolation procedures, the level of confidence associated with derived criteria, and the manner in which the data are aggregated in constructing the distribution. Advantages of the SSD approach include the fact that it uses the full range of available data, and the ability of the assessor to choose a level of protection and a level of uncertainty associated with a guideline value.

In the present study, the PNEC calculated by use of the SSD approach with a $50 \%$ certainty based on Chinese resident species was $0.057 \mathrm{mg} \mathrm{L}^{-1}$. This PNEC value can be recommended as a water quality criteria for 2,4,6-TCP to aquatic organisms protection in Chinese aquatic ecosystem. In spite of the violation of some assumptions (OECD, 1995) and disadvantages associated with SSD (Posthuma et al., 2002), SSD methods still have many advanta-
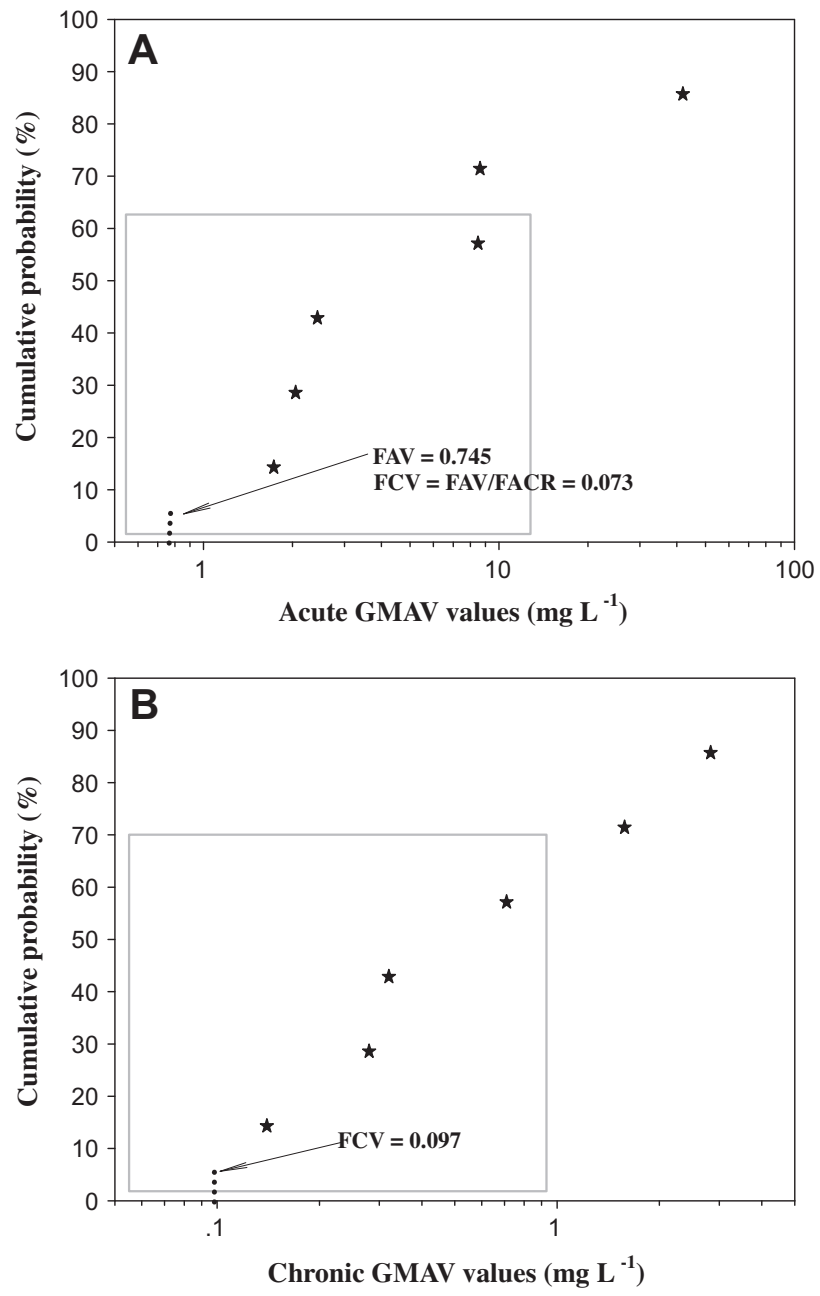

Fig. 5. PNECs for 2,4,6-trichlorophenol calculated using the USEPA acute-to-chronic (ACR) approach (A) and final chronic value (FCV) approach (only the lowest four toxicity values are used) (B).

ges over AF methods in criteria derivation. Of particular importance to risk managers is the ability to select appropriate centile and confidence levels, which is not possible in AF methods. So far, PNECs derived from SSDs have proven to be protective of ecosystems. However, a major limitation is the scarcity of suitable toxicity data, particular for site-specific chronic data. It is recommended that, depending on the toxicant, toxicity information for at least $10-15$ species are necessary to improve precision (Wheeler et al., 2002). Therefore, chronic toxicity data of various pollutants for site-specific species are critically needed for more accurate ecological risk assessment. Because chronic toxicity data are insufficient, the less predictive assessment factor methods are used in preliminary ecological risk assessment. 


\section{Conclusions}

The results of this study contribute to the assessment of the effect of 2,4,6-trichlorophenol in the aquatic environment, particularly with respect to local species and chronic studies. Responses to 2,4,6-TCP exposure varied with organisms - fishes and macroinvertebrates were more sensitive than hydrophytes. Comparing different methods of PNEC derivation AF methods was found to be over-conservative for these site-specific organisms. A PNEC of $0.057 \mathrm{mg} \mathrm{L}^{-1}$ derived using SSD method was recommended for Chinese aquatic ecosystem protection.

\section{Acknowledgements}

This research was financially supported by National Basic Research Program of China (2007CB407301), National Natural Science Foundation of China (20737003), and Ministry of Environmental Protection of the People's Republic of China (201009032). Prof. Giesy was supported by the Canada Research Chair program, an at large Chair Professorship at the Department of Biology and Chemistry and State Key Laboratory in Marine Pollution, City University of Hong Kong, The Einstein Professor Program of the Chinese Academy of Sciences and the Visiting Professor Program of King Saud University.

\section{References}

Aldenberg, T., Jaworska, J.S., 2000. Uncertainty of the hazardous concentration and fraction affected for normal species sensitivity distributions. Ecotoxicol. Environ. Saf. 46, 1-18.

Aldenberg, T., Slob, W., 1993. Confidence-limits for hazardous concentrations based on logistically distributed NOEC toxicity data. Ecotoxicol. Environ. Saf. 25, 48 63.

ANZECC \& ARMCANZ, 2000. Australian and New Zealand guidelines for fresh and marine water quality. Australian and New Zealand Environmentent and Conservation Council and Agriculture and Resource management Council of Australia and New Zealand, Canberra, Australia.

ASTM, 1993. Standard guide for conducting acute toxicity tests with fishes, macroinvertebrates and amphibians. Annual Book of ASTM Standards. American Society of Testing and Materials, Philadelphia, PA, USA. pp. 88-729.

Campbell, E., Palmer, M.J., Shao, Q., Warne, M.S.J., Wilson, D., 2000. BurrliOZ: A computer program for calculating toxicant trigger values for the ANZECC and ARMCANZ water quality guidelines. Perth, Western Australia, Australia.

Chapman, P.M., Fairbrother, A., Brown, D., 1998. A critical evaluation of safety (uncertainty) factors for ecological risk assessment. Environ. Toxicol. Chem. 17, 99-108.

Crossland, N.O., 1985. A method to evaluate effects of toxic chemicals on fish growth. Chemosphere 14, 1855-1870.

Czaplicka, M., 2004. Sources and transformations of chlorophenols in the natural environment. Sci. Total Environ. 322, 21-39.

$\mathrm{ECB}, 2003$. Technical guidance document on risk assessment in support of commission directive 93/67/EEC on risk assessment for new notified substances, commission regulation (EC) no. 1488/94 on risk assessment for existing substances, derective 98/8/EC of the European Parliament and of the Council concerning the placing of biocidal products on the market. Part II. Environmental Risk Assessment. European Chemicals Bureau, European Commission Joint Research Center, European Communities.
Gao, J.J., Liu, L.H., Liu, X.R., Zhou, H.D., Huang, S.B., Wang, Z.J., 2008. Levels and spatial distribution of chlorophenols 2,4-dichlorophenol, 2,4,6-trichlorophenol, and pentachlorophenol in surface water of China. Chemosphere 71, 1181-1187.

Hose, G.C., Van den Brink, P.J., 2004. Confirming the species-sensitivity distribution concept for endosulfan using laboratory, Mesocosm, and field data. Arch. Environ. Contam. Toxicol. 47, 511-520.

Kishino, T., Kobayashi, K., 1995. Relation between toxicity and accumulation of chlorophenols at various $\mathrm{Ph}$, and their absorption mechanism in fish. Water Res. 29, 431-442.

LeBlanc, G.A., Bionomics, E.G.G., 1984. Comparative structure-toxicity relationships between acute and chronic effects to aquatic organisms. D Reidel Pub Co., p. 235.

Mallett, M.J., Grandy, N.J., Lacey, R.F., 1997. Interlaboratory comparison of a method to evaluate the effects of chemicals on fish growth. Environ. Toxicol. Chem. 16, 528-533.

Newman, M.C., Ownby, D.R., Mezin, L.C.A., Powell, D.C., Christensen, T.R.L., Lerberg, S.B., Anderson, B.A., 2000. Applying species-sensitivity distributions in ecological risk assessment: assumptions of distribution type and sufficient numbers of species. Environ. Toxicol. Chem. 19, 508-515.

OECD, 1995. Guidance Document for Aquatic Effect Assessment. In: Organization for Economic Co-peration and Development (Ed.), Paris.

OECD, 2002. OECD Guidelines for the Testing of Chemicals, Revised Proposal for a New Guidelines 221, Lemna sp. Growth Inhibition Test. OECD, Paris, France.

Posthuma, L., Suter, G.W., Traas, T.P., 2002. Species Sensitivity Distributions in Ecotoxicology. Lewis Publishers, CRC Press, Boca Raton, FL.

Radix, P., Leonard, M., Papantoniou, C., Roman, G., Saouter, E., Gallotti-Schmitt, S., Thiebaud, H., Vasseur, P., 1999. Comparison of Brachionus calyciflorus 2-D and Microtox (R) chronic 22-h tests with Daphnia magna 21-d test for the chronic toxicity assessment of chemicals. Environ. Toxicol. Chem. 18, 2178-2185.

Shao, Q., 2000. Estimation for hazardous concentrations based on NOEC toxicity data: an alternative approach. Environmetrics 11, 583-595.

Sijm, D., De Bruijn, J., Crommentuijn, T., Van Leeuwen, K., 2001. Environmental quality standards: endpoints or triggers for a tiered ecological effect assessment approach? Environ. Toxicol. Chem. 20, 2644-2648.

Slooff, W., 1992. RIVM Guidance Document, Ecotoxicological Effect Assessment: Deriving Maximum Tolerable Concentrations (MTC) from Single-Species Toxicity Data. Report 719102018. National Institute for Public Health and the Environment, Bilthoven, The Netherlands.

Smith, A.D., Bharath, A., Mallard, C., Orr, D., Smith, K., Sutton, J.A., Vukmanich, J., McCarty, L.S. Ozburn, G.W. 1991. The acute and chronic toxicity of ten chlorinated organic compounds to the American flagfish (Jordanella floridae). Arch. Environ. Contam. Toxicol. 20, 94-102.

USEPA, 1985. Guidelines for Deriving Numerical National Water Quality Criteria for the Protection of Aquatic Organisms and Their Uses. National Technical Information Service Accession Number PB85-227049. US Environmental Protection Agency, Washington, D.C.

USEPA, 1990. Dunett Program Version 1.5, Probit Program Version 1.5, and Trimmed Spearman-Karber (TSK) Program Version 1.5, Ecological Monitoring Research Division. Environmental Monitoring Systems Laboratory, USEPA, Cincinnati, OH, USA.

USEPA, 1993. Methods for Measuring the Acute Toxicity of Effluents and Receiving Waters to Freshwater and Marine Organisms. United States Environmental Protection Agency, Cincinnati, Ohio, USA.

Wheeler, J.R., Grist, E.P.M., Leung, K.M.Y., Morritt, D., Crane, M., 2002. Species sensitivity distributions: data and model choice. Mar. Pollut. Bull. 45, 192-202.

Yin, D.Q., Hu, S.Q., Jin, H.J., Yu, L.W., 2003a. Deriving freshwater quality criteria for 2,4,6-trichlorophenol for protection of aquatic life in China. Chemosphere 52, 67-73.

Yin, D.Q., Jin, H.J., Yu, L.W., Hu, S.Q., 2003b. Deriving freshwater quality criteria for 2,4-dichlorophenol for protection of aquatic life in China. Environ. Pollut. 122, 217-222.

Yuan, X.H., Yang, Z.H., 1983. Botanic Physiological and Biochemical Test. Advanced Education Publishing Company, Beijing, China.

Zhang, T., Jin, H.J., 1997. Use of duckweed (Lemna minor L.) growth inhibition test to evaluate the toxicity of acrylonitrile, sulphocyanic sodium and acetonitrile in China. Environ. Pollut. 98, 143-147. 